\title{
Modification of Al-Si Alloys by Ce or Ce with $\mathrm{Sr}$
}

\author{
MARIO DE GIOVANNI, ${ }^{1}$ JAMES A. KADUK, ${ }^{2}$ \\ and PRAKASH SRIRANGAM ${ }^{1,3}$ \\ 1.-Warwick Manufacturing Group (WMG), University of Warwick, Coventry CV4 7AL, UK. 2.-Poly \\ Crystallography, Inc., Naperville, IL 60540-5407, USA. 3.—e-mail: p.srirangam@warwick.ac.uk
}

\begin{abstract}
Al-Si alloys were modified by addition of cerium (Ce) or Ce plus strontium (Sr) to study the effect on the eutectic silicon ( $\mathrm{Si}$ ) morphology. The modified alloys were characterized using scanning electron microscopy (SEM), x-ray diffraction (XRD) analysis, and thermal analysis to understand the effect of Ce and $\mathrm{Sr}$ on their microstructure. The results showed that addition of $1 \%$ Ce resulted in only partial modification of the Si phase, whereas addition of Ce with $0.04 \%$ $\mathrm{Sr}$ resulted in complete modification of the alloy. Addition of $1 \%$ Ce decreased the eutectic arrest temperature by about $10^{\circ} \mathrm{C}$, compared with a $5^{\circ} \mathrm{C}$ drop with $\mathrm{Sr}$ addition only. SEM energy-dispersive spectroscopy (EDS) and XRD results revealed formation of $\mathrm{Al}_{2} \mathrm{Si}_{2}$ Ce intermetallic in the Ce-modified $\mathrm{Al}-\mathrm{Si}$ alloys. Differential scanning calorimetry (DSC) showed that the intermetallic formed just before the eutectic phase.
\end{abstract}

\section{INTRODUCTION}

Aluminum-silicon (Al-Si) alloys are widely used in the automotive and aerospace industries due to their high strength-to-weight ratio, good castability, and excellent mechanical and performance properties. ${ }^{1}$ Slow solidification of such alloys produces a very coarse microstructure where the eutectic is composed of large plates or needles of $\mathrm{Si}$ in a continuous aluminum matrix. Alloys exhibiting this microstructure show low ductility due to the large and brittle $\mathrm{Si}$ plates. However, this coarse $\mathrm{Si}$ morphology can be modified into a fine and fibrous one by increasing the cooling rate or via chemical modification, improving the ductility and tensile strength of the alloy. ${ }^{1,2}$ The first chemical modifier used industrially was sodium $(\mathrm{Na})$. However, since the $1970 \mathrm{~s}$, the preferred modification element has been strontium (Sr), mainly due to its higher retention in the cast alloy and the lack of significant overmodification issues. Such microstructural modification can improve the mechanical properties, pressure tightness, and machinability, reduce the hot tear resistance, and significantly increase the fracture toughness of the alloy. ${ }^{1-3}$

Significant research has been carried out into the effect of various chemical elements, such as rare earths, for modification of Al-Si alloys. ${ }^{4-9}$ Even though most rare-earth elements are chemically and crystallographically similar to strontium, their addition only results in refinement of the microstructure of Al-Si alloys. One such example is cerium (Ce). Previous research has shown that addition of $1 \% \mathrm{Ce}$ to $\mathrm{Al}-\mathrm{Si}$ alloys results in only partial modification of the Si morphology and an improvement in the mechanical properties of the alloy. ${ }^{10}$ The Si morphology can be further refined by increasing the amount of $\mathrm{Ce}$ added to the alloy, whilst a fine fibrous structure can be obtained by combining Ce and chill casting. ${ }^{9}$

The mechanism by which such modification occurs has been greatly debated. Most theories focus on either growth-restriction-based mechanisms, mainly impurity-induced twinning (IIT) ${ }^{11,12}$ or restricted growth ${ }^{13}$ or nucleation-based effects, focusing on the formation of $\mathrm{Al}_{2} \mathrm{Si}_{2} \mathrm{Sr}$ (or similar) particles that deactivate eutectic Si nucleation sites. ${ }^{14-16}$

The aim of this work is to provide a basis to study the mechanistic differences between full modification, as achieved by using $\mathrm{Sr}$, and the partial modification achieved by Ce. This is done by quantifying the modification achieved, characterizing the solidification of the alloys by thermal analysis, and identifying any intermetallics formed. The synergistic effect of combining $\mathrm{Ce}$ with $\mathrm{Sr}$ on the modification of the eutectic $\mathrm{Si}$ morphology in $\mathrm{Al}-\mathrm{Si}$ hypoeutectic alloys is also investigated. 


\section{METHODOLOGY}

\section{Alloy Preparation}

Al-Si hypoeutectic alloy was prepared by melting 99.999\% purity $\mathrm{Al}$ (NewMet, UK) and 99.999\% Si (Alfa Aeser, UK) in a clay graphite crucible using a Carbolite RHF1500 high-temperature furnace. Once the alloy was molten at $750^{\circ} \mathrm{C}$, the metal was stirred using a graphite rod, poured into a preheated clay graphite crucible, and left to solidify. The cast Al-Si alloy was then used to prepare the modified alloys. The Al-Si alloy was remelted to allow for addition of Ce and Sr metals in the form of $\mathrm{Al}-10 \mathrm{Ce}$ (wt.\%) and $\mathrm{Al}-10 \mathrm{Sr}$ (wt.\%) master alloy. These alloys were poured into a preheated cylindrical graphite mold. The master alloys were produced similarly using the same $99.999 \%$ purity $\mathrm{Al}$ and $99 \%$ purity $\mathrm{Sr}$ (Alfa Aeser, UK) and 99.8\% purity Ce (Alfa Aeser, UK), respectively. Four alloys were prepared with the following approximate compositions: Al-8 wt.\%Si, Al-8 wt.\%Si-0.04 wt.\% Sr, Al8 wt.\%Si-1 wt.\%Ce, and Al-8 wt.\%Si-1 wt.\%Ce$0.04 \mathrm{wt} . \% \mathrm{Sr}$. The chemical composition of each alloy was analyzed using inductively couple plasma optical emission spectroscopy (ICP-OES) (Supplementary Table SI). These concentrations of $\mathrm{Ce}$ and $\mathrm{Sr}$ in the alloys were chosen based on previous research and industrial practice. ${ }^{2,9,10}$

\section{X-Ray Diffraction (XRD)}

The unmodified and modified Al-Si alloys and master alloys were analyzed by XRD at Poly Crystallography Inc. (Naperville, USA) using a Bruker D2 Phaser diffractometer equipped with a LynxEye position-sensitive detector. The metal samples were mounted in a deep sample holder using modeling clay. The x-ray powder patterns were measured from $5^{\circ}$ to $130^{\circ}$ in steps of $0.0202144^{\circ}$ at scan speed of $0.5 \mathrm{~s}$ per step, using a 0.6 -mm divergence slit with $2.5^{\circ}$ Soller slits and a 3mm scatter screen height.

\section{Microstructural Analysis}

Metallographic samples for microstructural analysis were prepared from the cast cylinders by grinding and mechanical polishing. Etching was performed using a mixture of $20 \%$ hydrochloric acid (conc. 37\%) and 80\% isopropyl alcohol to reveal the fibrous or lamellar structure of the Si eutectic. The analysis was carried out by means of optical microscopy and on a Zeiss-Sigma field emission gun-scanning electron microscope (FEG-SEM). Quantitative dimensional analysis of the Si phase was performed by analyzing five images acquired by $\mathrm{SEM}$ at $\times 5 \mathrm{k}$, using ImageJ $1.50 \mathrm{i}$ software. Chemical analysis was performed using energy-dispersive spectroscopy (EDS). The electron backscatter diffraction (EBSD) capability of the same SEM was also used to elucidate the grain misorientations in primary and eutectic $\mathrm{Al}$.

\section{Thermal Analysis}

The progress of solidification in the four samples was analyzed by examining their respective cooling curves. Approximately $15 \mathrm{~g}$ of each sample were placed in a clay graphite crucible and melted at $750^{\circ} \mathrm{C}$ in an electrical resistance furnace. Once molten, the crucible was taken out and a K-type thermocouple was immediately inserted below the surface of the melt. The cooling curve was collected using a data logger recording at $10 \mathrm{~Hz}$. Under these conditions, a cooling rate of $1.2 \pm 0.2^{\circ} \mathrm{C} / \mathrm{s}$ was observed. The measurement was repeated to ensure repeatability.

\section{Differential Scanning Calorimetry (DSC)}

Thermal analysis by means of DSC was conducted on the prepared alloys using a Netzsch STA 449 F3 Jupiter to determine the phase changes taking place. These experiments were conducted in inert argon (Ar) atmosphere at heating and cooling rate of $10 \mathrm{~K} / \mathrm{min}$, repeating the melting-solidification cycle for three times. Due to the overlapping peaks of the eutectic and primary $\mathrm{Al}$, the peaks were plotted using OriginPro ${ }^{\circledR} 2016$ (64-bit) b9.3.226 and biGuassian multiple peak fit analysis was carried out to obtain the eutectic onset temperature.

\section{RESULTS AND DISCUSSION}

\section{X-Ray Diffraction Analysis}

Figure 1 presents the XRD spectra of the four alloys under investigation and the master alloys from which they were produced. The peaks of interest in each spectrum are indicated with an asterisk, except in $\mathrm{Al}-\mathrm{Si}$, where the $\mathrm{Al}$ and $\mathrm{Si}$ peaks are differentiated using an asterisk and a circle, respectively. Figure $1 \mathrm{a}, \mathrm{b}$, and $\mathrm{c}$ shows the spectra for Al-Si, Al-Sr, and Al-Si-Sr. The spectrum for Al$\mathrm{Si}-\mathrm{Sr}$ is identical to that for Al-Si, thus yielding no information with respect to whether $\mathrm{Al}_{4} \mathrm{Sr}$ is still present in the alloy or whether a ternary intermetallic phase formed. However, previously published research demonstrated that Al-Si-Sr ternary intermetallic particles form in this specific alloy and constitute $0.03 \%$ by volume of the alloy. ${ }^{17}$ The lack of a peak for this component in Fig. 1c is due to the extremely small amount of $\mathrm{Sr}$ added in this alloy.

Figure $1 \mathrm{~d}$, e, and $\mathrm{f}$ presents the XRD spectra for $\mathrm{Al}-\mathrm{Ce}, \mathrm{Al}-\mathrm{Si}-\mathrm{Ce}$, and Al-Si-Ce-Sr. The dominant phase in $\mathrm{Al}-\mathrm{Ce}$ was $\mathrm{Al}_{11} \mathrm{Ce}_{3}$, changing to $\mathrm{Al}_{2} \mathrm{Si}_{2} \mathrm{Ce}$ when Al-Ce was added to Al-Si. Previous research has indicated that $\mathrm{Al}_{2} \mathrm{Si}_{2} \mathrm{Ce}$ is a metastable phase and that the thermodynamically favored phase at similar compositions would be $\mathrm{AlSi}_{2} \mathrm{Ce} .{ }^{18}$ However, the XRD results seem to indicate that, under these casting conditions, the metastable $\mathrm{Al}_{2} \mathrm{Si}_{2} \mathrm{Ce}$ forms.

When compared with the $\mathrm{Sr}$ addition in $\mathrm{Al}-\mathrm{Si}-\mathrm{Sr}$, the amount of Ce added in Al-Si-Ce and Al-Si-Ce-Sr is much greater, thus the amount of intermetallics formed is also significantly increased. The spectra 

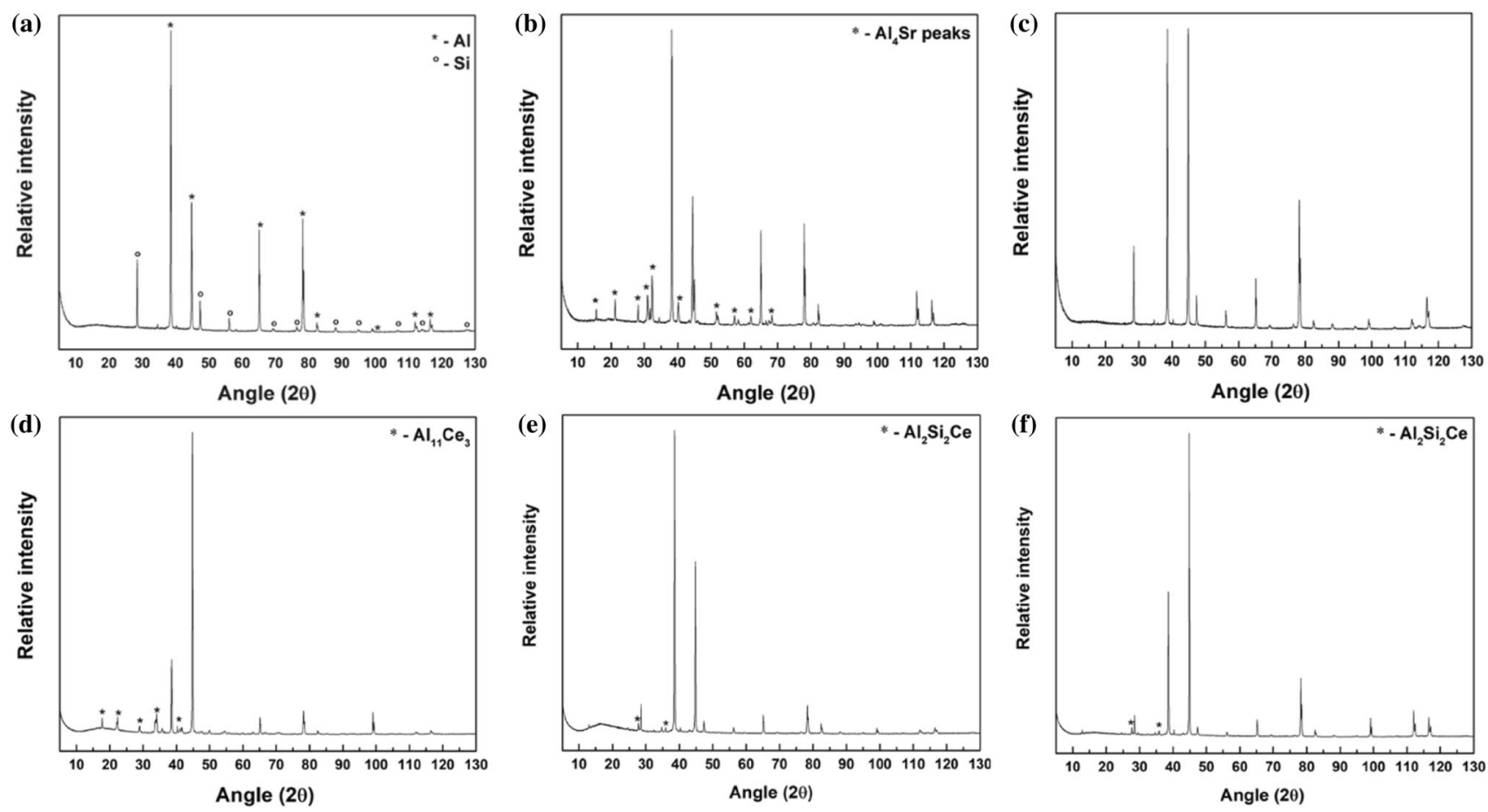

Fig. 1. XRD spectra of (a) Al-Si, (b) Al-Sr, (c) Al-Si-Sr, (d) Al-Ce, (e) Al-Si-Ce, and (f) Al-Si-Ce-Sr.

for Al-Si-Ce and Al-Si-Ce-Sr are identical, indicating that XRD is unable to identify the presence of any new particles formed or changes to the $\mathrm{Al}_{2} \mathrm{Si}_{2} \mathrm{Ce}$ due to the $\mathrm{Sr}$ addition.

\section{Microstructural Characterization}

Figure 2a, d, g, and $\mathrm{j}$ shows optical microscopy images of the unmodified and modified alloys. In Fig. 2a, the unmodified alloy shows primary $\mathrm{Al}$ and eutectic Si in the form of elongated plates, whilst Fig. $2 \mathrm{~d}$ shows the Sr-modified alloy, where addition of Sr resulted in modification of the eutectic Si to a fine fibrous structure. Figure $2 \mathrm{~g}$ shows that addition of $1 \%$ Ce caused refinement of the eutectic $\mathrm{Si}$ compared with the unmodified condition. The combined effect of $\mathrm{Ce}$ and $\mathrm{Sr}$ is shown in Fig. 2j, where the eutectic Si closely approaches full modification to a fine fibrous structure, though some longer $\mathrm{Si}$ features can be observed. In the alloys containing Ce, large block-like features, indicated by an arrow, can also be noted. These are Ce-containing intermetallics which form in the alloy.

Figure 2 also shows SEM images of the polished (b, e, h, k) and etched (c, f, i, l) alloy samples. The images obtained from the polished samples can be considered as a high-magnification version of the optical images. Note that the $\mathrm{Si}$ in the $\mathrm{Al}-\mathrm{Si}$ (b) alloy is present in a flake-like structure, whilst the Al-Si$\mathrm{Sr}$ (e) and Al-Si-Ce-Sr (k) show very similar microstructures, i.e., a fine fibrous one. On the other hand, the Al-Si-Ce (h) sample shows a partially modified microstructure, as both flake-like and fiber-like $\mathrm{Si}$ can be observed. The etched samples provide further understanding on the microstructural modification by imaging the $\mathrm{Si}$ at subsurface level. The Si flake-like structure of Al-Si is confirmed in Fig. 2c. The fine fibrous $\mathrm{Si}$ microstructure in $\mathrm{Al}-\mathrm{Si}-\mathrm{Sr}$ and $\mathrm{Al}-\mathrm{Si}-\mathrm{Ce}-\mathrm{Sr}$ can also be seen in Fig. 2f and l, respectively. These images indicate an almost identical Si morphology in both of these alloys. Further insight is provided for Al-SiCe in Fig. 2l, which shows a central flake-like feature in the shape of an "X" surrounded by fibers. This confirms that $1 \%$ Ce only partially modified the Si phase, as observed in previous studies. ${ }^{4,9,10}$

The modification effect in the different alloys was analyzed quantitatively in terms of the Feret diameter and circularity by analyzing five SEM images. It must be clarified that this quantitative analysis was performed on a two-dimensional (2D) crosssection and thus yields information regarding the apparent size and shape of the Si eutectic in this plane. The Feret diameter is defined as the longest distance between any two points along the selection boundary. ${ }^{19}$ The circularity is defined as $4 \pi \times \frac{\text { Area }}{\text { Perimeter }}$, where a value of 1 indicates a perfect circle, with decreasing values indicating less circular features. ${ }^{19}$ Alloys presenting shorter and more circular Si features can be considered to have achieved a higher degree of modification. The results of this analysis are presented as histograms in Fig. 3. Figure $3 \mathrm{a}$ shows the Feret diameter distribution of the Si features across the whole range, while the inset zooms in on the region from $0 \mu \mathrm{m}$ to $2 \mu \mathrm{m}$. Figure $3 \mathrm{~b}$ shows the circularity 

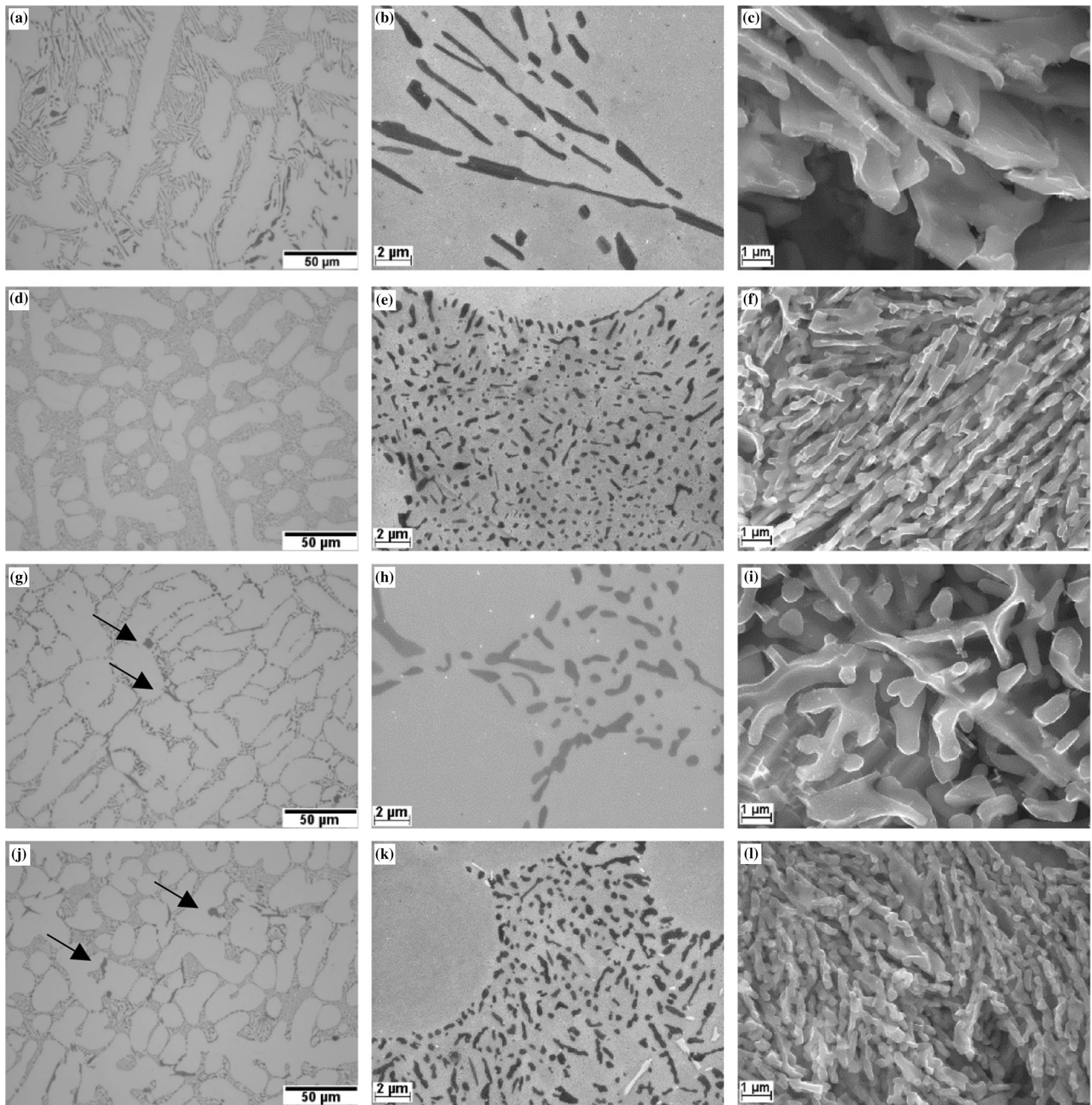

Fig. 2. Optical microscopy images (a, d, g, j) and scanning electron microscopy images on unetched (b, e, h, k) and etched (c, f, i, l) samples of Al-Si (a-c), Al-Si-Sr (d-f), Al-Si-Ce (g-i), and Al-Si-Ce-Sr (j-l).

distribution of the Si phase. Tabulated data are also shown as insets to these figures.

Figure 3 shows a distinct trend between the two alloys that contain $\mathrm{Sr}$ and the two that do not. Al-Si$\mathrm{Sr}$ and $\mathrm{Al}-\mathrm{Si}-\mathrm{Ce}-\mathrm{Sr}$ both present $\mathrm{Si}$ features with markedly smaller average Feret diameter and higher average circularity, indicating that a significantly higher degree of modification was achieved. $\mathrm{Al}-\mathrm{Si}$ showed slightly longer and significantly less circular $\mathrm{Si}$ features compared with $\mathrm{Al}-\mathrm{Si}-\mathrm{Ce}$, indicating that addition of $1 \%$ Ce partially modified the
Si within the microstructure. On the other hand, the two Sr-containing alloys presented similarly sized and shaped Si. A slight difference in the circularity of these alloys can be observed in Fig. 3b. $\mathrm{Al}-\mathrm{Si}-\mathrm{Ce}-\mathrm{Sr}$ seemed to show a slightly higher percentage of features with lower circularity $(<0.8)$ compared with Al-Si-Sr. Though only marginal, this could be further confirmation of the observations made based on the SEM microstructures, i.e., the presence of longer features in Al-Si-Ce-Sr compared with Al-Si-Sr. 

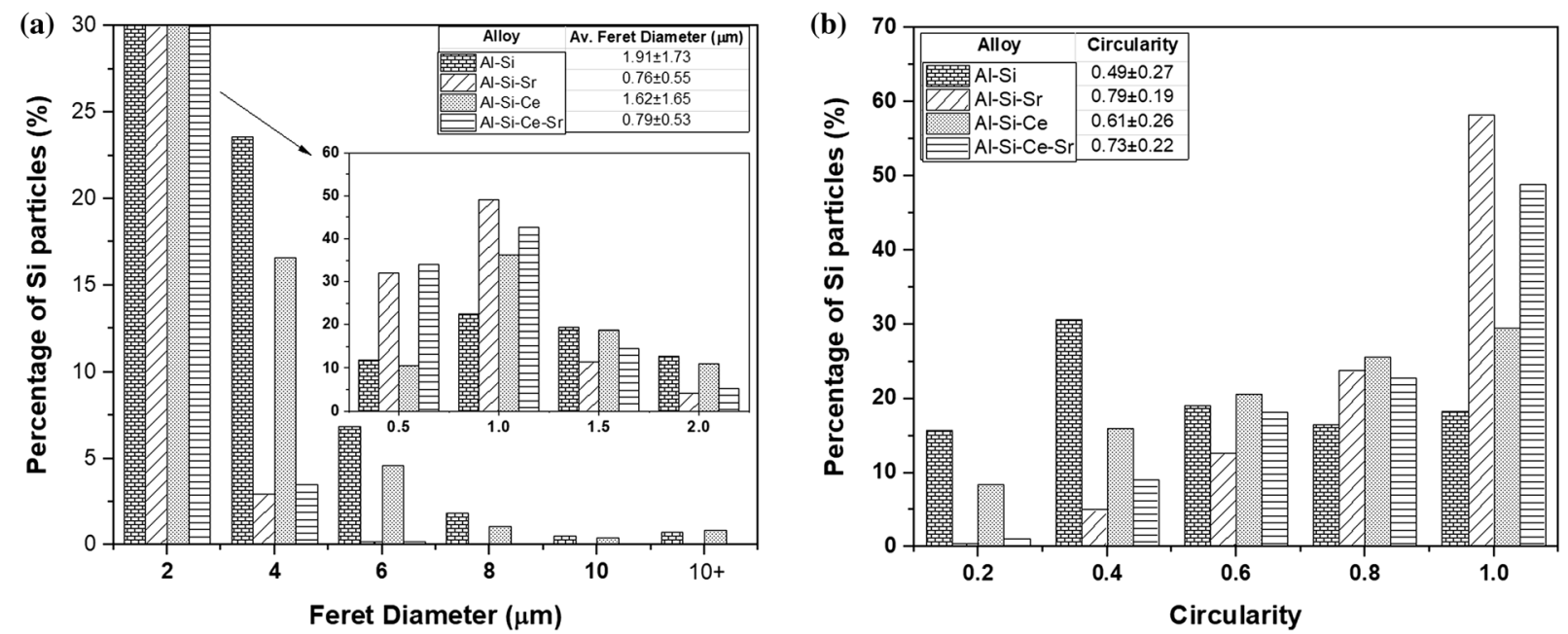

Fig. 3. (a) Size distribution analysis of the Si phase comparing Al-Si, Al-Si-Sr, Al-Si-Ce, and Al-Si-Ce-Sr, (b) shape distribution analysis for the same alloys. The table insets show average values and standard deviation for the alloys.

\section{Thermal Analysis}

Figure 4 shows the eutectic region of the cooling curves for each of the four different alloy compositions. The complete cooling curves are provided in Supplementary Fig. S1. The nucleation temperature $\left(T_{\mathrm{N}}\right)$, minimum temperature $\left(T_{\mathrm{MIN}}\right)$, growth temperature $\left(T_{\mathrm{G}}\right)$, and recalescence $\left(T_{\mathrm{G}}-T_{\mathrm{MIN}}\right)$ were measured. The eutectic $T_{\mathrm{N}}$ is the point at which Si crystals start to nucleate. It can be extracted from the cooling curves by plotting the derivative of the curve and reading out where the tangents of the two slopes meet. $T_{\mathrm{MIN}}$ is the point where the eutectic $\mathrm{Si}$ and $\mathrm{Al}$ have grown to a stage where the latent heat evolved during the growth process balances the heat flow out of the system. $T_{\text {MIN }}$ leads to recalescence, which takes place when the release of latent heat exceeds the heat extraction from the system. This results in a new heat balance, which is denoted as $T_{\mathrm{G}}{ }^{20}$ These results show that addition of $1 \%$ Ce extended the mushy zone, as the primary growth temperature increased whilst the eutectic arrest temperature decreased. This allows for further growth of primary $\mathrm{Al}$. The eutectic nucleation decreased by $5^{\circ} \mathrm{C}$ upon adding $400 \mathrm{ppm}$ Sr. Upon adding $1 \% \mathrm{Ce}$, the nucleation temperature was depressed by a further $5^{\circ} \mathrm{C}$, whereas upon addition of both $\mathrm{Ce}$ and $\mathrm{Sr}$, the nucleation temperature increased by about $2^{\circ} \mathrm{C}$ in comparison with addition of $1 \% \mathrm{Ce}$ only. The depression of the eutectic growth temperature is frequently regarded as an indication of the microstructural modification obtained. This is normally attributed to the aluminum phosphide (AlP) nucleation sites becoming poisoned by the modifying element, causing eutectic nucleation to occur at a lower temperature. However, in this case, note that the depression of the eutectic growth temperature does not reflect the microstructural modification obtained. This has also been observed by other

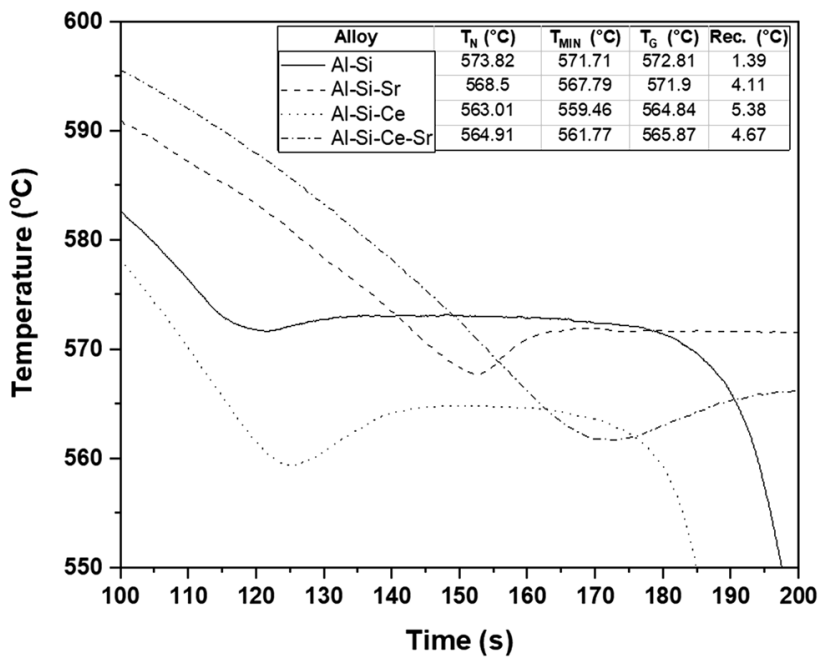

Fig. 4. Comparison of the eutectic region of the cooling curves of Al$\mathrm{Si}, \mathrm{Al}-\mathrm{Si}-\mathrm{Sr}, \mathrm{Al}-\mathrm{Si}-\mathrm{Ce}$, and Al-Si-Ce-Sr.

authors when adding rare-earth elements to $\mathrm{Al}-\mathrm{Si}$ alloys. ${ }^{10,20,21}$ There is also a marked difference in the eutectic recalescence, which increased from $1.4^{\circ} \mathrm{C}$ for unmodified $\mathrm{Al}-\mathrm{Si}$ to approximately $5^{\circ} \mathrm{C}$ in presence of $\mathrm{Ce}$, in both $\mathrm{Al}-\mathrm{Si}-\mathrm{Ce}$ and $\mathrm{Al}-\mathrm{Si}-\mathrm{Ce}-\mathrm{Sr}$. The depression in the eutectic growth temperature, for all three modified alloys, seems to indicate that $\mathrm{Al}_{2} \mathrm{Si}_{2} \mathrm{X}$ compounds, where $\mathrm{X}$ could be either $\mathrm{Ce}$ or $\mathrm{Sr}$, deactivates any AlP from acting as nucleating sites for the eutectic. The greater extent to which the eutectic growth temperature is affected in the Ce-containing alloys may be related to their higher Ce content. The lack of nucleation sites and therefore more homogenous nucleation is shown by the smaller but nevertheless flake-like $\mathrm{Si}$ structure. Therefore, the decrease in eutectic growth can be related to the removal of nucleation sites and more homogenous nucleation, but not to the 
morphological transition to a fiber-like eutectic observed in the presence of Sr. Furthermore, note that supercooling $\left(T_{\mathrm{G}}-T_{\mathrm{N}}\right)$ was observed for all the alloys, except the unmodified alloy. Hanna et al. showed that supercooling occurs in hypoeutectic $\mathrm{Na}$ modified Al-Si alloy but not in unmodified alloy, indicating that the modification affects the nucleation of eutectic $\mathrm{Si}^{22}$ The fact that the same effect can be seen in $\mathrm{Al}-\mathrm{Si}$ alloys containing both $\mathrm{Sr}$ or $\mathrm{Ce}$ indicates that both of these elements affect the nucleation of eutectic Si.

\section{Differential Scanning Calorimetry}

DSC was primarily used to identify the temperature of formation of any intermetallic phases, since no indication of these was observed in the cooling curves. DSC was also used as a cross-check for the trends observed in the cooling curves. Figure 5 shows the second cooling cycle during the DSC analysis of the different samples. The inset table presents the average and standard deviation of the primary and eutectic onsets for the three cooling cycles. Note from the DSC curves that, for all the modified alloys, the primary onset occurred much earlier. This is similar to what was observed in the cooling curves, though it is more evident now, due to the slower cooling rates. The interpretation of the eutectic onset is more difficult, as it overlaps with the primary onset. Bi-Gaussian curve fitting was performed, and the first deviation from the baseline of the eutectic curve was extracted as the eutectic onset.

One of the first observations is that the eutectic onset for the unmodified $\mathrm{Al}-\mathrm{Si}$ occurred at $587^{\circ} \mathrm{C}$ rather than the well-known equilibrium eutectic temperature of $577^{\circ} \mathrm{C}$. This indicates that the curve fitting used here can only be used to correlate trends between the alloys being analyzed rather than for comparison with more general, absolute values. Nonetheless, for all the modified samples, the eutectic onset occurred at a much lower temperature than for the unmodified sample. The $\mathrm{Sr}$ modified sample exhibited a eutectic onset temperature similar to the Ce-containing samples. This contrasts with the cooling curve data, where the eutectic nucleation temperature was significantly higher for Al-Si-Sr compared with Al-Si-Ce or Al-SiCe-Sr. For the Ce-containing samples, an inflection occurred at the beginning of the eutectic formation, being more evident for $\mathrm{Al}-\mathrm{Si}-\mathrm{Ce}$. This difference between the results of the two techniques can be attributed to the inflection in the curve. In fact, comparison of the peak position shows that, for the Ce-containing samples, the peak occurs at a much later stage than for Al-Si-Sr. This inflection is attributed to the formation of intermetallics in the alloy.

It was also generally observed that samples containing $\mathrm{Sr}$ showed lower standard deviation than the other alloys. During this analysis, it was noted that minimal oxidation occurred on the Srcontaining samples, which retained their shiny appearance, indicating that, under these conditions, a thick oxide layer did not form. On the other hand, the alloys that did not contain $\mathrm{Sr}$ turned dull, indicating formation of an oxide layer. This oxide formation explains the drift from the first to third cycle and the higher standard deviation for the alloys that did not contain Sr.

A number of authors previously employed DSC to measure the undercooling in $\mathrm{Al}-\mathrm{Si}$, using melt-spun alloys. In such cases, two distinct peaks formed for the eutectic formation, the first representing solidification of eutectic $\mathrm{Si}$ along grain boundaries and the second representing solidification of entrained eutectic Si within the Al matrix. ${ }^{23,24}$ In some cases, when exploring the effect of addition of trace amounts of modification elements such as strontium and europium, detection of intermetallic compound formation was also achieved, appearing as a small peak just after the first eutectic peak. ${ }^{25,26}$ In this study, intermetallic formation was detected just at the start of the eutectic formation. The addition of $\mathrm{Sr}$ to Al-Si-Ce also seems to bring the intermetallic formation forward slightly.

\section{Energy-Dispersive Spectroscopy}

EDS chemical composition maps for the Al-Si and $\mathrm{Al}-\mathrm{Si}$ modified alloys were acquired and are presented in Supplementary Fig. S2, clearly showing the segregation of $\mathrm{Al}$ and $\mathrm{Si}$ in their respective phases. Furthermore, they show that, in the presence of $\mathrm{Ce}$, intermetallic phases made up of all three elements formed. For Al-Si-Sr and Al-Si-Ce-Sr, the Sr map is also presented, although its concentration within these areas was too low to be detected. The presence of $\mathrm{Al}_{2} \mathrm{Si}_{2} \mathrm{Sr}$ intermetallics in $\mathrm{Al}-\mathrm{Si}-\mathrm{Sr}$ has been previously shown by EDS and quantified by $\mathrm{x}$ ray computed tomography (XCT). ${ }^{17}$

These results show that, in such systems, ternary intermetallic compounds in the form of $\mathrm{Al}_{2} \mathrm{Si}_{2} \mathrm{X}$ form as an intrinsic part of the solidification process. Previous research has debated the formation of $\mathrm{Al}_{2} \mathrm{Si}_{2} \mathrm{Sr}$ as a crucial aspect of the nucleation and subsequent modification of the eutectic $\mathrm{Si}^{16,27}$ The formation of $\mathrm{Al}_{2} \mathrm{Si}_{2} \mathrm{Ce}$ and the lack of full modification in the Al-Si-Ce alloy indicate that the formation of such compounds is not a crucial factor in predicting the modification potential of an element. Some authors have debated whether the formation of nanoclusters, with different shapes, of $\mathrm{Al}_{2} \mathrm{Si}_{2} \mathrm{Sr}$ within eutectic $\mathrm{Si}$ is the contributing factor for the modification potential of $\mathrm{Sr}^{28,29}$ Therefore, further work, by means of transmission electron microscopy and atom probe tomography, is required to fully characterize the eutectic Si partially modified by Ce, and to explore whether such nanoclusters also form after addition of Ce. 


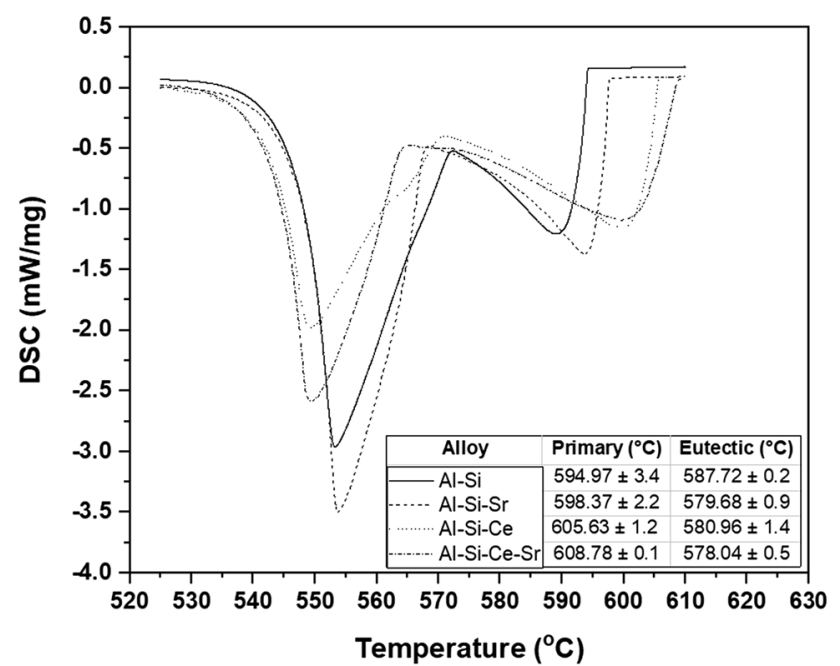

Fig. 5. Comparison of the second cooling cycle in DSC analysis of Al-Si, Al-Si-Sr, Al-Si-Ce, and Al-Si-Ce-Sr.

\section{Electron Backscatter Diffraction}

Large-area EBSD misorientation maps were acquired on the four alloys and are presented in Supplementary Fig. S3. Different grain colors indicate misorientation greater than $5^{\circ}$. From these maps it can be noted that, in unmodified $\mathrm{Al}-\mathrm{Si}$, the primary $\mathrm{Al}$ dendrite orientation extends within the eutectic Al. This indicates that the solidification of the eutectic $\mathrm{Al}$ occurred mainly on primary $\mathrm{Al}$ dendrites. There are also some areas in the Al-Si map that seem to have nucleated separately from the primary dendrite, but when comparing the Al-Si EBSD map with the Al-Si-Sr one, a stark contrast can be noted immediately. The latter shows complete separation between the primary and eutectic $\mathrm{Al}$, as individual areas within the eutectic have different orientations relative to each other and relative to the primary. In the $\mathrm{Al}-\mathrm{Si}-\mathrm{Ce}$ and $\mathrm{Al}-\mathrm{Si}$ Ce-Sr alloys, though not as evident primarily due to
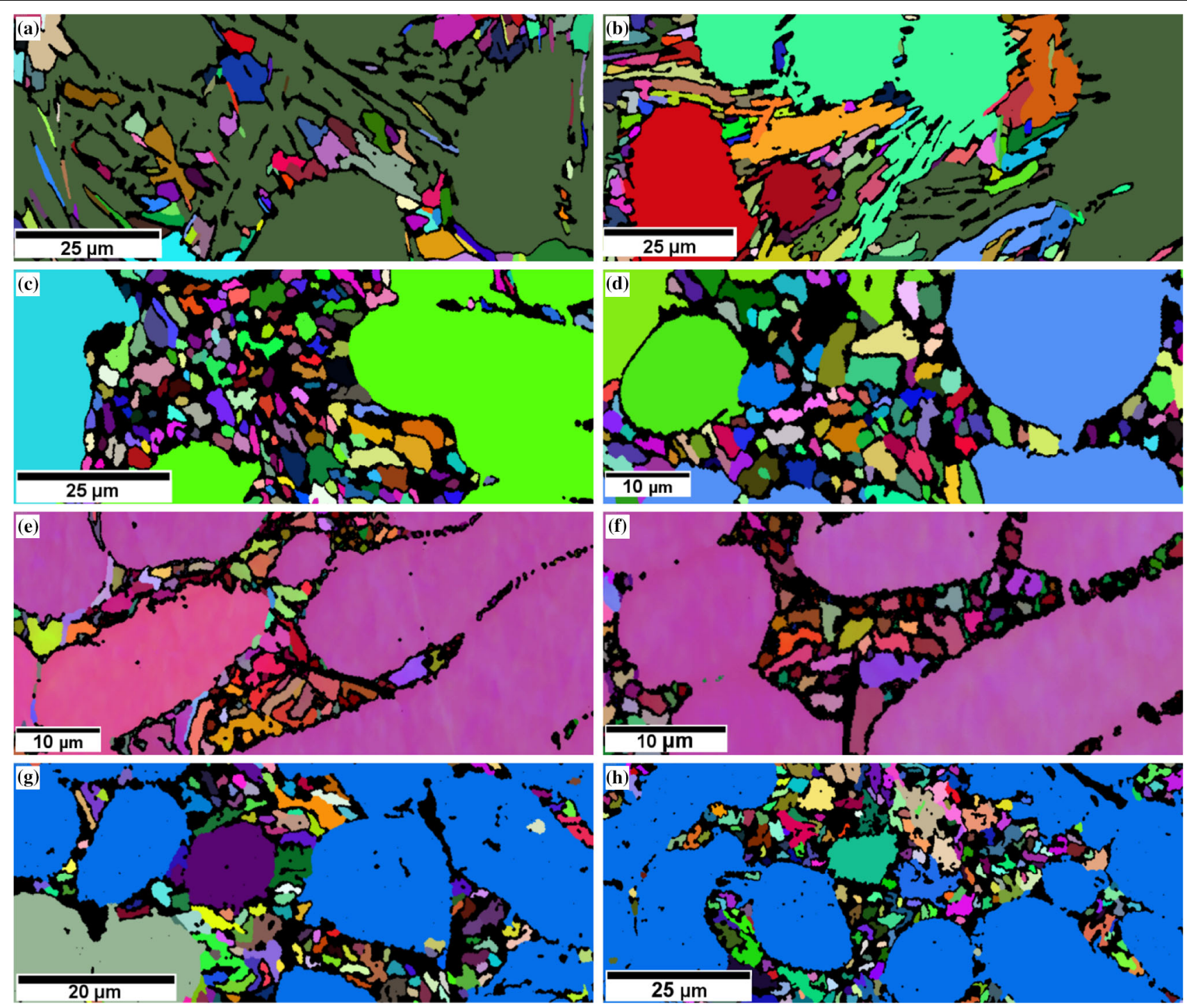

Fig. 6. EBSD maps for (a, b) Al-Si, (c, d) Al-Si-Sr, (e, f) Al-Si-Ce, and (g, h) Al-Si-Ce-Sr. (Color figure available online). 
the smaller eutectic region, a similar observation can be made.

Magnified images from different regions of each EBSD map are provided in Fig. 6, as these provide more detailed information. Images from the $\mathrm{Al}-\mathrm{Si}$ map are shown in Fig. 6a and b. Note that most of the eutectic $\mathrm{Al}$ region has the same orientation as the primary $\mathrm{Al}$ in proximity (dark green in a, bright green in b). However, there are also grains which show a misorientation from the primary $\mathrm{Al}$.

EBSD has been previously employed to shed light on the solidification behavior of Sr-modified and unmodified Al-Si alloys. ${ }^{14,30-33}$ Most of this research explored the Al solidification. Nogita and Dahle ${ }^{30}$ argue that, if the eutectic $\mathrm{Al}$ nucleates on the primary $\mathrm{Al}$ dendrite, the orientation of the eutectic $\mathrm{Al}$ would be the same as that of the primary dendrite, whereas if the eutectic $\mathrm{Al}$ nucleates in the interdendritic liquid, the orientation would be different from that of the primary $\mathrm{Al}$ dendrite. Their results indicated a transition from the former to latter mechanism upon modifying alloy 319 with $70 \mathrm{ppm}$ Dahle et al. ${ }^{14}$ agreed with this observation, but noted that, at higher levels of $\mathrm{Sr}$, the eutectic $\mathrm{Al}$ growth reverted back to growth in the same orientation as the primary $\mathrm{Al}$ dendrite whilst still achieving complete modification of the $\mathrm{Si}$ phase. Heiberg and Arnberg ${ }^{32}$ noted the same mechanism when using high-purity alloys modified with $150 \mathrm{ppm}$ Sr. The results presented herein indicate a general trend which shows that, in the presence of $\mathrm{Ce}$ and/or Sr, the solidification of the eutectic $\mathrm{Al}$ occurs independently from the primary $\mathrm{Al}$ dendrite, as individual eutectic $\mathrm{Al}$ regions have different orientations with respect to the primary $\mathrm{Al}$.

\section{CONCLUSION}

- Addition of $1 \%$ Ce caused partial modification of $\mathrm{Al}-\mathrm{Si}$. Upon addition of $0.04 \% \mathrm{Sr}$ to $\mathrm{Al}-\mathrm{Si}-\mathrm{Ce}$, full modification was obtained, being comparable to the Sr modification employed industrially.

- Cooling curves and DSC results showed that the primary $\mathrm{Al}$ growth temperatures were increased in the presence of $1 \% \mathrm{Ce}$.

- Cooling curves and DSC results showed that the eutectic nucleation and growth temperatures were reduced. It is also noted that, in the presence of $1 \% \mathrm{Ce}$, the eutectic growth temperature was significantly lower than in the unmodified or Sr-modified Al-Si. Although this is normally regarded as an indication of the modification effect, microstructural examination of the Al-Si-Ce alloy showed otherwise.

- Addition of Ce caused formation of an intermetallic phase, identified as $\mathrm{Al}_{2} \mathrm{Si}_{2} \mathrm{Ce}$ by means of XRD and EDS.

- EBSD indicated that, in the presence of $\mathrm{Ce}$ and/ or $\mathrm{Sr}$, the solidification of the eutectic $\mathrm{Al}$ was completely independent of the primary Al. The fact that $\mathrm{Ce}$ and $\mathrm{Sr}$, a partial and full modifier, respectively, showed the same behavior indicates that the solidification of the eutectic $\mathrm{Al}$ in relation to the primary $\mathrm{Al}$ is not a contributing factor to the modification of the $\mathrm{Si}$ eutectic phase.

\section{ELECTRONIC SUPPLEMENTARY MATERIAL}

The online version of this article (https://doi.org/10. 1007/s11837-018-3192-6) contains supplementary material, which is available to authorized users.

\section{OPEN ACCESS}

This article is distributed under the terms of the Creative Commons Attribution 4.0 International License (http://creativecommons.org/licenses/by/4.0/), which permits unrestricted use, distribution, and reproduction in any medium, provided you give appropriate credit to the original author(s) and the source, provide a link to the Creative Commons license, and indicate if changes were made.

\section{REFERENCES}

1. I.J. Polmear, Light Alloy (Amsterdam: Elsevier, 2005), pp. 205-235.

2. R. Bartley, British and European Aluminium Casting Alloys (Birmingham: Association of Light Alloy Refiners, 1996).

3. J.E. Hatch, Aluminium: Properties and Physical Metallurgy, 2nd ed. (Materials Park: American Society of Metals, 1984).

4. K. Nogita, S.D. McDonald, and A.K. Dahle, Mater. Trans. $45,323(2004)$

5. B.J. Ye, Trans. Am. Foundrymen's Soc. 93, 533 (1985).

6. Z. Shi, Q. Wang, Y. Shi, G. Zhao, and R. Zhang, J. Rare Earths 33, 1004 (2015).

7. H. Qiu, H. Yan, and Z. Hu, J. Alloys Compd. 567, 77 (2013).

8. Y.C. Tsai, C.Y. Chou, S.L. Lee, C.K. Lin, J.C. Lin, and S.W. Lim, J. Alloys Compd. 487, 157 (2009).

9. V. Vijeesh and K.N. Prabhu, Light Metals 2015 (Hoboken: Wiley, 2015), pp. 403-407.

10. Y.C. Tsai, S.L. Lee, and C.K. Lin, J. Chin. Inst. Eng. 34, 609 (2011).

11. S. Lu and A. Hellawell, J. Cryst. Growth 73, 316 (1985).

12. S.-Z.S. Lu and A. Hellawell, Metall. Trans. A 18, 1721 (1987).

13. K.F. Kobayashi and L.M. Hogan, J. Mater. Sci. 20, 1961 (1985).

14. A.K. Dahle, K. Nogita, S.D. McDonald, J.W. Zindel, and L.M. Hogan, Metall. Mater. Trans. A 32, 949 (2001).

15. Y.H. Cho, H.-C. Lee, K.H. Oh, and A.K. Dahle, Metall. Mater. Trans. A 39, 2435 (2008).

16. P. Srirangam, S. Chattopadhyay, A. Bhattacharya, S. Nag, J. Kaduk, S. Shankar, R. Banerjee, and T. Shibata, Acta Mater. 65, 185 (2014).

17. M. De Giovanni, J.M.J.M. Warnett, M.A.M.A. Williams, and P. Srirangam, J. Alloys Compd. 727, 353 (2017).

18. J. Gröbner, D. Mirković, and R. Schmid-Fetzer, Metall. Mater. Trans. A 35, 3349 (2004).

19. W.R.T. Ferreira, ImageJ User Guide IJ 1.46r (2012).

20. J.H. Li and P. Schumacher, Int. J. Cast Met. Res. 25, 347 (2012). 
21. M.G. Mahmoud, E.M. Elgallad, M.F. Ibrahim, and F.H. Samuel, Int. J. Met. 12, 251 (2018).

22. M.D. Hanna, S. Lu, and A. Hellawell, Metall. Trans. A 15, 459 (1984).

23. C.R. Ho and B. Cantor, J. Mater. Sci. 30, 1912 (1995).

24. C. Liao, J. Chen, Y. Li, R. Tu, and C. Pan, J. Mater. Sci. Technol. 28, 524 (2012).

25. M. Zarif, B. Mckay, and P. Schumacher, Metall. Mater. Trans. A 42, 1684 (2010).

26. J.H. Li, X.D. Wang, T.H. Ludwig, Y. Tsunekawa, L. Arnberg, J.Z. Jiang, and P. Schumacher, Acta Mater. 84, 153 (2015).

27. J. Barrirero, M. Engstler, N. Ghafoor, N. de Jonge, M. Odén, and F. Mücklich, J. Alloys Compd. 611, 410 (2014).
28. J. Barrirero, J. Li, M. Engstler, N. Ghafoor, P. Schumacher, M. Odén, and F. Mücklich, Scr. Mater. 117, 16 (2016).

29. M. Timpel, N. Wanderka, R. Schlesiger, T. Yamamoto, D. Isheim, G. Schmitz, S. Matsumura, and J. Banhart, Ultramicroscopy 132, 216 (2013).

30. K. Nogita and A. Dahle, Mater. Charact. 46, 305 (2001).

31. K. Nogita, A. Knuutinen, S.D. McDonald, and A.K. Dahle, J. Light Met. 1, 219 (2001).

32. G. Heiberg and L. Arnberg, J. Light Met. 1, 43 (2001).

33. A.K. Dahle, K. Nogita, S.D. McDonald, C. Dinnis, and L. Lu, Mater. Sci. Eng. A 413-414, 243 (2005). 